\title{
Hemodynamics and arteriovenous malformations in cavopulmonary anastomosis: The case for residual antegrade pulsatile flow
}

\author{
Roland Henaine, MD, PhD, ${ }^{\mathrm{a}}$ Mathieu Vergnat, $\mathrm{MD},{ }^{\mathrm{a}}$ Olaf Mercier, MD, ${ }^{\mathrm{b}}$ Alain Serraf, MD, PhD, ${ }^{\mathrm{c}}$ \\ Vincent De Montpreville, MD, ${ }^{\mathrm{b}}$ Jean Ninet, $\mathrm{MD},{ }^{\mathrm{a}}$ and Emile A. Bacha, $\mathrm{MD}^{\mathrm{d}}$
}

\begin{abstract}
Objectives: Continuous flow in Fontan circulation results in impairment of pulmonary artery endothelial function, increased pulmonary vascular resistance, and, potentially, late failure of Fontan circulation. Bidirectional cavopulmonary shunt is the interim procedure in palliation of patients with single-ventricle physiology, but pulmonary arteriovenous malformations occur in many patients. In a porcine chronic model of cavopulmonary shunt, we studied pulmonary hemodynamics, pulmonary arteriovenous malformation occurrence, and gas exchange capabilities. We hypothesized that residual antegrade pulsatile pulmonary flow may attenuate the deleterious effects of nonpulsatile Fontan-type circulation.
\end{abstract}

\begin{abstract}
Methods: Thirty pigs underwent a sham procedure $(\mathrm{n}=10$, group I), a cavopulmonary shunt with right pulmonary artery ligation $(\mathrm{n}=10$, group II, nonpulsatile), or a cavopulmonary shunt with proximal right pulmonary artery partial ligation $(\mathrm{n}=10$, group III, micropulsatile). Three months later, in vivo hemodynamics, blood gas exchange, pulmonary arteriovenous malformation occurrence, and lung histology were assessed.
\end{abstract}

Results: At 3 months, group II right lungs demonstrated significantly increased pulmonary artery pressure, pulmonary vascular resistance, and evidence of pulmonary arteriovenous malformations compared with groups I and III (all $P<.001$ ). Group III lungs also showed increased pulmonary artery pressure and pulmonary vascular resistance compared with the sham group, but significantly less than group II. Group III right lungs had the best gas exchange performance, with less histologic changes compared with group II.

Conclusions: We developed a viable chronic large animal model of bidirectional cavopulmonary anastomosis. Residual antegrade pulsatile flow in the setting of a cavopulmonary shunt prevents pulmonary arteriovenous malformation formation and attenuates, but does not suppress, the development of pulmonary hypertension. From a clinical standpoint, these data would support keeping a small amount of antegrade pulsatile flow during creation of a cavopulmonary shunt. (J Thorac Cardiovasc Surg 2013;146:1359-65)

During the past 40 years, the Fontan procedure has significantly changed the outcome of patients born with single-ventricle physiology. However, despite significant improvements in perioperative morbidity, mortality, and long-term outcomes, ${ }^{1,2}$ a so-called failing Fontan state looms at the horizon for most patients. The physiology leading to the failing Fontan is characterized by increased pulmonary vascular impedance, decreased vascular recruitment, and increased pulmonary vascular resistance (PVR) and diastolic dysfunction.

\footnotetext{
From the Department of Cardiothoracic Surgery, ${ }^{a}$ Hôpital Louis Pradel, Hospices Civils de Lyon, Lyon, France; Laboratoire de Chirurgie Expérimentale, ${ }^{\mathrm{b}}$ Hôpital Marie Lannelongue, Université Paris Sud, Le Plessis Robinson, France; Department of Pediatric Cardiac Surgery, ${ }^{c}$ Jacques Cartier Hospital, Massy, France; and Pediatric Cardiac Surgery, ${ }^{\mathrm{d}}$ New York-Presbyterian/Morgan Stanley Children's Hospital, Columbia University Medical Center, New York, NY.

Disclosures: Authors have nothing to disclose with regard to commercial support.

Received for publication Sept 20, 2012; revisions received Jan 22, 2013; accepted for publication Feb 13, 2013; available ahead of print March 13, 2013.

Address for reprints: Roland Henaine, MD, PhD, Department of Cardiac Surgery, Cardiologic Hospital Louis Pradel, Ave du Doyen Lépine, 69394 Lyon, France (E-mail: roland.henaine@chu-lyon.fr).

0022-5223/ $\$ 36.00$

Copyright (c) 2013 by The American Association for Thoracic Surgery

http://dx.doi.org/10.1016/j.jtcvs.2013.02.036
}

The bidirectional Glenn cavopulmonary shunt (CPS) represents the standard interim procedure in the palliation of patients with single-ventricle physiology toward eventual Fontan circulation. ${ }^{3,4}$ Its performance provides excellent palliation of single ventricles and has resulted in decreased mortality compared with the Fontan procedure without this intermediate step. ${ }^{5}$

Despite these advantages, concerns remain, many having to do with the pulmonary vasculature. Pulmonary arteriovenous malformations (PAVM) ${ }^{6}$ and systemic to pulmonary arterial collaterals ${ }^{7}$ tend to develop in patients palliated with a Glenn alone. Durability of this palliation is limited by the likelihood of developing PAVM and progressive cyanosis.

To prevent the "natural history" of the failing Fontan, some authors recently proposed to suppress the Fontan completion step and palliate patients with singleventricle physiology with only bidirectional CPS. ${ }^{8}$ In many Third World countries, palliation of singleventricle physiology is achieved by bidirectional CPS alone. In this setting, strategies to avoid the occurrence of PAVM include the use of additional pulmonary blood flow. 


$$
\begin{aligned}
& \text { Abbreviations and Acronyms } \\
& \mathrm{CPS}=\text { cavopulmonary shunt } \\
& \mathrm{FIO}_{2}=\text { inspired oxygen fraction } \\
& \mathrm{PA}=\text { pulmonary artery } \\
& \mathrm{PAP}=\text { pulmonary artery pressure } \\
& \mathrm{PCO}_{2}=\text { partial pressure of carbon dioxide } \\
& \mathrm{Po}_{2}=\text { partial pressure of oxygen } \\
& \mathrm{PVP}=\text { pulmonary vein pressure } \\
& \mathrm{PVR}=\text { pulmonary vascular resistance } \\
& \mathrm{SaO}=\text { arterial oxyhemoglobin saturation } \\
& \mathrm{SVC}=\text { superior vena cava }
\end{aligned}
$$

We have developed a model to investigate the benefits of antegrade flow in the bidirectional CPS setting, as well as the potential for reduction of pulmonary hypertension by maintenance of antegrade pulsatility. We used a chronic large animal model of nonpulsatile pulmonary circulation and investigated the changes in physiology, hemodynamics, gas exchange, and lung histology. Our hypothesis was that maintenance of residual antegrade pulsatile flow would lead to a "higher quality" palliation as measured by improved gas exchange, less PAVM, and reduced pulmonary artery pressure (PAP).

\section{MATERIALS AND METHODS}

Thirty large white pigs weighing $20 \pm 2 \mathrm{~kg}$ were used in this study. All animals received humane care in compliance with the Principles of Laboratory Animal Care formulated by the National Society for Medical Research and the Guide for the Care and Use of Laboratory Animals published by the National Institutes of Health (publication No. 85-23, revised 1996).

\section{Study Groups}

The piglets were randomly allocated to 3 groups ( $\mathrm{n}=10 \mathrm{in}$ each): Group I included animals that were studied 3 months after dissection of the right pulmonary artery (PA) with no other surgery (sham group). Group II included animals that were studied 3 months after superior vena cava (SVC) to right PA anastomosis with ligation of the proximal right PA (nonpulsatile group). Group III included animals that were studied 3 months after SVC to right PA anastomosis with calibrated banding of the proximal right PA (micropulsatile group).

\section{Surgical Procedures}

Anesthesia was induced with intramuscular ketamine $(10 \mathrm{mg} / \mathrm{kg})$ and atropine sulfate $(0.2 \mathrm{mg} / \mathrm{kg})$, and maintained with intravenous pentobarbital $(10 \mathrm{mg} / \mathrm{kg}$ bolus, followed by a continuous infusion of 0.1 $\mathrm{mg} / \mathrm{kg} / \mathrm{min})$.

The animals were paralyzed with pancuronium $(0.3 \mathrm{mg} / \mathrm{kg})$. After endotracheal intubation, intermittent positive-pressure ventilation was provided (MMS RET 107 ventilator; MMS, Pau, France) at a tidal volume of 10 $\mathrm{mL} / \mathrm{kg}$, a respiratory rate of $18 \mathrm{cycles} / \mathrm{min}$, and an inspired oxygen fraction $\left(\mathrm{FIO}_{2}\right)$ of 0.5 . Body temperature was kept constant at $37^{\circ} \mathrm{C}$.

A midline sternotomy was performed under sterile conditions, and the pericardium was opened. Baseline hemodynamic and gazometric data were recorded before further manipulations. The SVC was dissected, and the azygos and right thoracic veins were ligated and divided to allow full mobilization of SVC. The right PA also was dissected up to the superior upper lobe branch.

Heparin (100 IU/kg) was administered. For group I (sham), no procedure was performed. For group II (nonpulsatile), the SVC was disconnected from right atrium and sutured on the right $\mathrm{PA}$, with ligation of the origin of the right PA. For group III (micropulsatile), a similar SVC to right PA anastomosis was performed, but the right PA was banded at its origin using a 3-mm Hegar dilator. Figure 1 illustrates the surgical preparations.

Chest tube drainage was established, and the sternotomy was closed. The animals were allowed to recover. To avoid postoperative occlusion of the anastomosis, the animals were anticoagulated with fractionated heparin until the study was terminated.

\section{Hemodynamic and Blood Gas Measurements}

Hemodynamic values were recorded at each time point of the experiment: direct measurement of aortic pressure, PAP (trunk and right branch), SVC pressure, and left and right pulmonary vein pressures (PVPs); and blood flow rate (with ultrasonic peritubular transit timeflow probes and T106/T206 Animal Research Flowmeter [Transonic System Inc, Ithaca, NY]) of the aorta, PA trunk, and PA left and right branches.

The PVR was calculated separately for either lung by the standard formula applying mean pressure in each PA, left atrial pressure, and flow in each PA. Blood samples were drawn in the aorta, the pulmonary arterial trunk, and, after anastomosis, in the right and left pulmonary arteries and right and left pulmonary veins. By using the Rapidlab 348 (Bayer Corp, Pittsburgh, Pa) blood gas analyzer, immediate measurement of partial pressure of carbon dioxide $\left(\mathrm{PCO}_{2}\right)$ and partial pressure of oxygen $\left(\mathrm{PO}_{2}\right)$ was performed, and the arterial oxyhemoglobin saturation $\left(\mathrm{SaO}_{2}\right)$ was calculated assuming a standard oxyhemoglobin dissociation curve. Hemodynamic and blood gas analyses were performed before and after anastomosis and at study termination.

\section{Pulmonary Arteriovenous Malformation Screening}

Tests were performed at postoperative month 3 . Under general anesthesia, the animal was placed in the supine position, and the right jugular vein and right femoral vessels were exposed under sterile conditions through a short incision.

First, arterial blood gases were obtained by the femoral artery. Measurements of arterial $\mathrm{Po}_{2}$ at an $\mathrm{FIO}_{2}$ of 0.21 and 1 (10-minute exposure) were obtained. A ratio of these $\mathrm{Po}_{2}\left(\mathrm{Po}_{2}-1 / \mathrm{Po}_{2}-0.21\right)$ inferior to 5 indicated the presence of PAVM. ${ }^{9}$

The introducer sheath was placed into the jugular and femoral veins. Transthoracic contrast echocardiography was performed. Ten milliliters of a saline solution and air mixture $(8 \mathrm{~mL}$ and $2 \mathrm{~mL}$, respectively) was agitated to produce bubbles and injected sequentially into the superior and inferior vena cavae. The appearance of bubbles in the left atrium within 3 cardiac cycles after injection indicates AV shunting. ${ }^{10}$

Finally, 5F Berman angiographic catheters (Arrow International, Reading, $\mathrm{Pa}$ ) were placed in the right and left PAs under fluoroscopic guidance. Correct patency of the anastomosis was first controlled by contrast medium injection in the SVC. The catheter was then positioned close to the PA branch bifurcation, and contrast medium was injected to document PAVM in the right and left lungs. The catheters and introducer sheath were then removed, the vessels were repaired, and the skin was sutured. The animals were allowed to recover.

\section{Tissue Harvest}

Study termination was performed 1 week after PAVM screening. Under general anesthesia, a left posterolateral thoracotomy was performed, and hemodynamic and blood gas data were collected. Subsequently, a right thoracotomy was performed, and respective hemodynamic and blood gas data were collected. Pigs were then anticoagulated with sodium heparin $(300 \mathrm{U} / \mathrm{kg}$ ) and euthanized by exsanguination under deep anesthesia. The lungs were removed for histology sampling. 

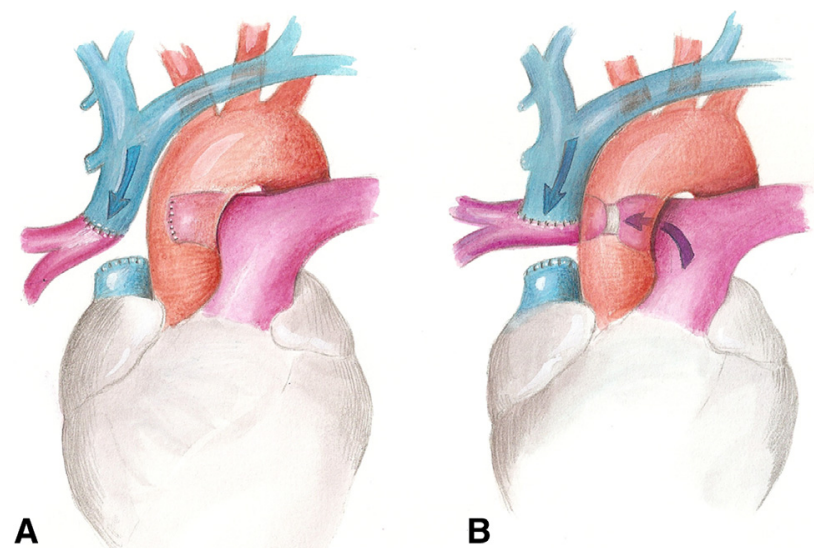

FIGURE 1. Diagram of the animal model. A, In group II (nonpulsatile), an SVC to right PA anastomosis (Glenn shunt) was performed, with complete ligation of the proximal right PA. B, In group III (micropulsatile), a similar anastomosis was performed with partial calibrated ligation of the right PA.

The right and left lung inferior lobe fragments were harvested, and tissues were fixed in $10 \%$ buffered formalin and imbedded in paraffin. Sections (4- $\mu \mathrm{m}$ thick) were subsequently cut for light microscopy and stained with hematoxylin phloxine saffron and orcein-picroindigocarmine.

\section{Statistics}

Data are expressed as mean \pm standard deviation. Statistical analysis was performed for comparison between groups at each time point, between each time point among the same groups, and between the right and left lungs in the same animal (intra individual control). Data were analyzed with a software package (Statview IV; Abacus Concepts, Berkeley, Calif). Hemodynamic comparisons were performed using a paired Student $t$ test.

\section{RESULTS \\ Hemodynamics}

Baseline characteristics and hemodynamics were similar between groups (Table 1). At 3 months, right PAP was significantly increased in both groups II and III compared with sham-operated controls. Group II had significantly higher right PAP compared with group III $(P=.0005)$. Right PVP was significantly increased in group II compared with groups I and III, whereas group III demonstrated no statistical variation compared with the sham group.

PVR in the right lung was significantly higher in group II compared with group I $(P=.001)$ and group III $(P=.001)$. Right lung PVR was significantly elevated in group III compared with group I $(P=.001)$, but to a lesser extent than in group II.

For the left lung, PAP significantly increased in groups II $(P=.019)$ and III $(P=.05)$ compared with group I, but with no difference between groups II and III. No difference was found between groups for PVP and PVR.

For intraindividual (right vs left) comparison, no difference was found in sham group I, except for higher left PVR $(P=.001)$. For group II, right PAP, right PVP, and

TABLE 1. Changes in pulmonary hemodynamics

\begin{tabular}{|c|c|c|c|c|c|}
\hline & \multirow[b]{2}{*}{ Group } & \multicolumn{2}{|c|}{ Baseline } & \multicolumn{2}{|c|}{$3 \mathrm{mo}$} \\
\hline & & Right lung & Left lung & Right lung & Left lung \\
\hline \multirow[t]{3}{*}{ Weight, kg } & I & \multicolumn{2}{|c|}{$20.0 \pm 0.7$} & \multicolumn{2}{|c|}{$40.2 \pm 7.98$} \\
\hline & II & \multicolumn{2}{|c|}{$21.6 \pm 2.7$} & \multicolumn{2}{|c|}{$53.6 \pm 6.73$} \\
\hline & III & \multicolumn{2}{|c|}{$19.0 \pm 2.5$} & \multicolumn{2}{|c|}{$45.6 \pm 2.51$} \\
\hline \multirow[t]{3}{*}{ Mean AoP, mm Hg } & I & \multicolumn{2}{|c|}{$52.8 \pm 12.4$} & \multicolumn{2}{|c|}{$82.3 \pm 25.1$} \\
\hline & II & \multicolumn{2}{|c|}{$56.6 \pm 7.4$} & \multicolumn{2}{|c|}{$57.3 \pm 5.82$} \\
\hline & III & \multicolumn{2}{|c|}{$54.0 \pm 3.1$} & \multicolumn{2}{|c|}{$70 \pm 19.2$} \\
\hline \multirow[t]{3}{*}{ Mean PAP, mm Hg } & I & $9.0 \pm 2.8$ & $10.9 \pm 1.8$ & $11.1 \pm 0.6$ & $12.6 \pm 1.3$ \\
\hline & II & $9.6 \pm 3.8$ & $10.4 \pm 1.9$ & $26.7 \pm 1.3 *, \ddagger$ & $19.4 \pm 4.7^{*}, \ddagger$ \\
\hline & III & $8.8 \pm 2.7$ & $11.8 \pm 1.3$ & $14.2 \pm 0.8^{*}$ & $17.9 \pm 4.4^{*}, \ddagger$ \\
\hline \multirow[t]{3}{*}{ Mean PVP, mm Hg } & I & \multicolumn{2}{|c|}{$3.9 \pm 1.4 \S$} & $7.1 \pm 0.2$ & $7.4 \pm 1.5$ \\
\hline & II & \multicolumn{2}{|c|}{$4.6 \pm 1.0 \S$} & $14.1 \pm 3.0^{*}, \ddagger$ & $8.6 \pm 0.4 \ddagger$ \\
\hline & III & \multicolumn{2}{|c|}{$3.8 \pm 2.2 \S$} & $7.4 \pm 2.6$ & $8.8 \pm 0.7$ \\
\hline \multirow[t]{3}{*}{ Ao outflow, L/min } & $\mathrm{I}$ & \multicolumn{2}{|c|}{$1.90 \pm 0.13$} & \multicolumn{2}{|c|}{$2.34 \pm 0.58$} \\
\hline & II & \multicolumn{2}{|c|}{$2.10 \pm 0.47$} & \multicolumn{2}{|c|}{$2.57 \pm 0.45$} \\
\hline & III & \multicolumn{2}{|c|}{$2.00 \pm 0.22$} & \multicolumn{2}{|c|}{$2.32 \pm 0.24$} \\
\hline \multirow[t]{3}{*}{ PA outflow, L/min } & I & $1.27 \pm 0.05$ & $0.69 \pm 0.03 \ddagger$ & $1.70 \pm 0.58$ & $1.48 \pm 0.18 \ddagger$ \\
\hline & II & $1.32 \pm 0.27$ & $0.71 \pm 0.14 \ddagger$ & $1.82 \pm 0.04$ & $2.62 \pm 0.52 *, \dagger, \ddagger$ \\
\hline & III & $1.30 \pm 0.15$ & $0.70 \pm 0.08 \ddagger$ & $1.68 \pm 0.36$ & $2.16 \pm 0.37^{*}, \ddagger$ \\
\hline \multirow[t]{3}{*}{$\mathrm{PVR}, \mathrm{mm} \mathrm{Hg} \cdot \mathrm{min} / \mathrm{L}$} & I & $5.47 \pm 1.82$ & $10.16 \pm 3.20 \ddagger$ & $2.36 \pm 0.45$ & $3.56 \pm 0.82$ \\
\hline & II & $4.69 \pm 2.13$ & $8.70 \pm 3.73 \ddagger$ & $6.92 \pm 1.83^{*}, \dagger, \ddagger$ & $3.92 \pm 1.40 \ddagger$ \\
\hline & III & $6.23 \pm 1.37$ & $11.58 \pm 2.40 \ddagger$ & $4.20 \pm 1.36^{*}$ & $4.09 \pm 1.83$ \\
\hline
\end{tabular}

Values are means \pm standard deviation. $A o P$, Aortic pressure; $P A P$, pulmonary arterial pressure; $P V P$, pulmonary vein pressure; $A o$, aortic; $P A$, pulmonary artery; $P V R$, pulmonary vascular resistance. $*$ Significant difference compared with group I. †Significant difference compared with group III. $\ddagger$ Significant difference compared with contralateral side. $\S$ Right and left PVPs are identical and equal to left atrial pressure at baseline. Left atrial pressure is presented. 
TABLE 2. Pulmonary venoarterial difference at 3 months

\begin{tabular}{|c|c|c|c|c|c|c|c|c|c|}
\hline & \multicolumn{3}{|c|}{$\Delta \operatorname{va~Sao}(\%)$} & \multicolumn{3}{|c|}{$\Delta$ va $\mathrm{Po}_{2}(\mathrm{~mm} \mathrm{Hg})$} & \multicolumn{3}{|c|}{$\Delta \mathrm{va} \mathrm{PCO}_{2}(\mathrm{~mm} \mathrm{Hg})$} \\
\hline & Right & Left & & Right & Left & & Right & Left & \\
\hline Group I & $16.1 \pm 12.2$ & $17.3 \pm 6.8$ & $P=.7$ & $223.5 \pm 81.3$ & $147.7 \pm 109.8$ & $P=.09$ & $-8.5 \pm 12.4$ & $-9.9 \pm 9.1$ & $P=.7$ \\
\hline Group II & $27.7 \pm 0.9$ & $23.8 \pm 15.5$ & $P=.4$ & $193.6 \pm 72.8$ & $120.5 \pm 74.2$ & $P=.04$ & $-14.1 \pm 5.5$ & $-2.3 \pm 3.8$ & $P=.001$ \\
\hline Group III & $34.1 \pm 12.0$ & $25.5 \pm 6.9$ & $P=.06$ & $298.7 \pm 75.1$ & $168.2 \pm 62.4$ & $P=.001$ & $-17.3 \pm 7.5$ & $-3.4 \pm 5.1$ & $P=.001$ \\
\hline
\end{tabular}

Values are means \pm standard deviation. $\triangle \mathrm{va}$, Pulmonary venoarterial difference; $\mathrm{SaO}_{2}$, arterial oxyhemoglobin saturation; $\mathrm{Po}_{2}$, partial pressure of oxygen; $\mathrm{Pco}_{2}$, partial pressure of carbon dioxide.

right PVR were significantly higher compared with the left side $(P=.0003, .0004$, and .001 , respectively).

For group III, no statistically significant increase of PAP, PVP, and PVR was found in the right lung compared with the left lung. Of note, PAP was even lower in the right lung $(P=.003)$.

\section{Blood Gas Analysis}

Baseline data demonstrated no significant differences for

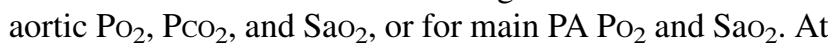
3 months, for intergroup comparison, the right lungs of groups II and III compared with group I demonstrated lower PA SaO $2(71.7 \% \pm 0.8 \%[P=.04]$ and $65.7 \% \pm 12.0 \%$ $[P=.01]$ vs $79.8 \% \pm 11.5 \%)$, lower $\mathrm{PA} \mathrm{Po}_{2}(37.4 \pm 0.7$ $\mathrm{mm} \mathrm{Hg}[P=.03]$ and $34.2 \pm 4.9 \mathrm{~mm} \mathrm{Hg}[P=.007]$ vs $42.0 \pm 6.5 \mathrm{~mm} \mathrm{Hg})$, and similar $\mathrm{PA}_{\mathrm{PCO}_{2}}(29.8 \pm 0.7 \mathrm{~mm}$ $\mathrm{Hg}[P=.08]$ and $37.3 \pm 10.8 \mathrm{~mm} \mathrm{Hg}[P=.9]$ vs $37.5 \pm$ $13.5 \mathrm{~mm} \mathrm{Hg}$ ), respectively. The gas exchange efficiency of the right and left lungs at 3 months in each group is shown in Table 2.

Despite lower $\mathrm{SaO}_{2}$ and $\mathrm{Po}_{2}$ in the right $\mathrm{PA}$, significantly higher pulmonary oxygen transfer was found with higher pulmonary venoarterial difference for $\mathrm{SaO}_{2}$ in groups II $(P=.007)$ and III $(P=.003)$ and higher pulmonary venoarterial difference for arterial oxygen tension in group III $(P=.04)$. Carbon dioxide clearance was better in groups II and III, but without reaching significant difference $(P=.2$ and $P=.07)$.

For intraindividual comparison, no difference was found between the right and left lungs in sham group I. In groups II and III, as expected, no difference was found between right and left PA blood gas. Right versus left PA $\mathrm{SaO}_{2}$ was $71.7 \%$ $\pm 0.8 \%$ versus $72.6 \% \pm 13.4 \%(P=.8)$ for group II and $65.7 \% \pm 12.0 \%$ versus $74.0 \% \pm 6.7 \%(P=.07)$ for group III; right and left $\mathrm{PA} \mathrm{Po}_{2}$ was $37.4 \pm 0.7 \mathrm{~mm} \mathrm{Hg}$ versus 36.5 $\pm 4.3 \mathrm{~mm} \mathrm{Hg}(P=.5)$ for group II and $34.2 \pm 4.9 \mathrm{~mm} \mathrm{Hg}$ versus $34.0 \pm 2.4 \mathrm{~mm} \mathrm{Hg}(P=.9)$ for group III; right and left $\mathrm{PA} \mathrm{PCO}_{2}$ was $29.8 \pm 0.7 \mathrm{~mm} \mathrm{Hg}$ versus $34.3 \pm 8.2$ $\mathrm{mm} \mathrm{Hg}(P=.09)$ for group II and $37.3 \pm 10.8 \mathrm{~mm} \mathrm{Hg}$ versus $31.9 \pm 3.3 \mathrm{~mm} \mathrm{Hg}(P=.1)$ for group III. Despite the similar arterial pulmonary blood gas between the right and left PA, groups II and III demonstrated significantly higher oxygen transfer and carbon dioxide clearance than group I (Table 2).

\section{Detection of Pulmonary Arteriovenous Malformation}

After the hyperoxic test (Figure 2), all animals had a $\mathrm{Po}_{2}-1 / \mathrm{Po}_{2}-0.21$ ratio superior to 5 for groups $\mathrm{I}(6.22 \pm$ $0.74)$ and III ( $5.43 \pm 0.27)$. All of the animals in group II had a ratio inferior to $5(4.43 \pm 0.35)$. Contrast echocardiography detected arteriovenous shunting in 8 of the 10 animals of group II. PAVM developed in the right lung but not the left lung. Arteriovenous shunting was absent in groups I and III. Atrial or ventricular septal defects were not present in any of the animals. No PAVM was demonstrated by PA angiography in all groups. The CPS was patent in all animals.

\section{Histology}

Lungs of group I animals were grossly normal when examined at the study termination. For all animals in group II, the surface of the right shunted lung was covered by subpleural vascular hyperplasia and severe lymphatic adhesions surrounded right PA (Figure 3, $A$ and $B$ ). Similar, but less remarkable, abnormalities were observed in group III right lungs. Left lungs of groups II and III were grossly normal. No histologic changes were found on the right and left lung extract from sham group I and on left lungs from groups II and III.

Right lung specimens of group II demonstrated several alterations unlike groups I and III (Figure 3, $C$-E). Venous

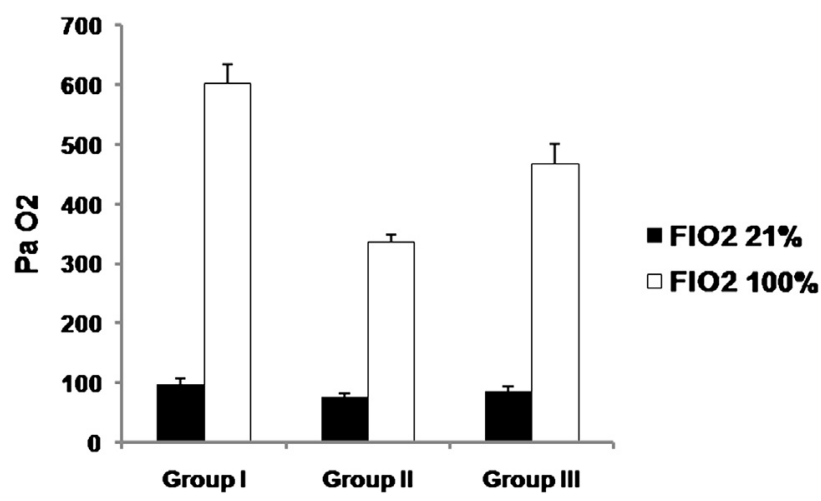

FIGURE 2. Detection of PAVM by hyperoxic test. Arterial oxygen tension at $\mathrm{FIO}_{2}$ of $21 \%$ for each group is represented by filled bars. Arterial oxygen tension after 10-minute exposure to $\mathrm{FiO}_{2}$ of $100 \%$ is shown in the open bars. Values are means \pm standard deviation. $\mathrm{Pao}_{2}$, Arterial oxygen tension; $\mathrm{Fio}_{2}$, inspired oxygen fraction. 


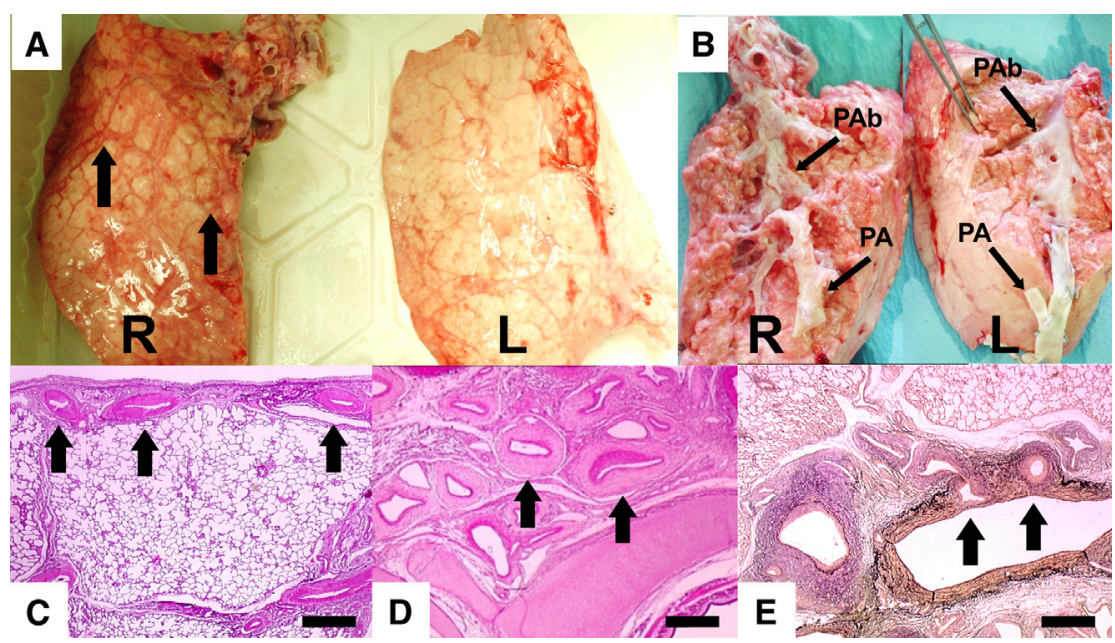

FIGURE 3. Macroscopic and histologic changes induced by CPS. A, Surfaces of the left and right lungs of pig representative of group II 3 months after CPS. Large and tortuous vessels are visible on the lung surface under visceral pleura on the right lung, but not on the left lung. B, PA of the left and right lungs of pig representative of group II 3 months after CPS . Right PA is surrounded by severe lymphatic adhesions, unlike left PA. C, D, and E, Example of lung sections ipsilateral to the cavopulmonary anastomosis obtained from a pig representative of group II 3 months after cavopulmonary anastomosis. Histologic images are stained with hematoxylin phloxine saffron, photographed at $\times 25$ (scale bar $=500 \mu \mathrm{m}$ ). Arrowheads demonstrate hyperplasia of venous wall under pleura (C), along bronchial axes and between alveolar lobules (D) of the shunted lung, penetrating veins in the wall of the pulmonary elastic artery (early sign of PAVM) in 6 animals of group II (E). R, Right; $L$, left; $P A$, pulmonary artery; PAb, pulmonary artery bed.

hyperplasia was noted along bronchial axes, between alveolar lobules, and under pleura. Venous wall thickness was enlarged, with muscular hyperplasia of the media. In 6 of the animals in group II, veins were identified within the wall of pulmonary elastic arterioles. No inflammatory signs were noted on any of the abnormal specimens.

\section{DISCUSSION}

The utility of residual antegrade pulmonary blood flow from the single ventricle into the pulmonary arteries, maintained after CPS, remains controversial. ${ }^{11}$ Such a strategy has been demonstrated to both improve and complicate the immediate postoperative and interstage clinical courses after the bidirectional CPS procedure. ${ }^{12-14}$

\section{The Model}

The chronic large animal model described in this study is the first to allow the study of the pulmonary vasculature exposed to nonpulsatile blood flow. Chronic models of Fontan circulation do not exist because total cavopulmonary connection is not viable in animals. However, our model exposes the right lung to a continuous flow regimen, mimicking the Fontan circulation, and allows the study of specific problems related to the CPS.

The fact that these animals survived and developed pulmonary hypertension, and, as demonstrated by echocardiography, hyperoxia test, and histology, demonstrated PAVM similar to that seen in humans demonstrates the validity of this model.
To study the effect of residual antegrade pulsatile flow, we added a group with a calibrated standardized amount of residual right PA lumen. We chose a residual diameter of $3 \mathrm{~mm}$, because we hypothesized that the residual antegrade pathway would occlude at less than $3 \mathrm{~mm}$. Performing a unilateral cavopulmonary anastomosis allows each animal to serve as its own control by comparison with the nonshunted lung.

We arbitrarily decided to terminate the study at 3 months, because preliminary studies demonstrated early consequences of nonpulsatile flow at this time. However, in this model, survival is possible beyond 3 months, for example, to test the effects of pharmaceutical agents used for longterm effects of the bidirectional CPS.

\section{Pulmonary Arteriovenous Malformations}

The development of PAVM after the classic Glenn anastomosis (SVC to right PA) is well documented with an incidence up to $25 \%{ }^{6}$ PAVM occurring after bidirectional CPS causes intrapulmonary right-to-left shunting, whereby systemic venous blood reaches the pulmonary venous system through abnormal vascular connections proximal to the gas exchange units. In recent years, the classic Glenn has been largely replaced by the bidirectional cavopulmonary anastomosis.

The incidence of PAVM after bidirectional Glenn has not been well characterized, but PAVM definitely occurs in this setting, ${ }^{6,15,16}$ although less frequently. Classic and bidirectional Glenn procedures favor the distribution of flow to the lower lobe, ${ }^{17}$ which is the site of preferential 
PAVM formation. Other factors of the Glenn physiology, such as low or no pulsatility or partial systemic desaturation, may be important.

Despite recognition of PAVM for more than 30 years, its exact pathogenesis remains unknown. It is presumed that the development of PAVM is related to the diversion of hepatic venous flow away from the pulmonary circulation. ${ }^{18}$ Although the absence of pulsatile flow may be a pathogenetic factor, data are scarce when other causes than the hepatic factor are studied. A recent report by Kwon and colleagues $^{19}$ on the development of PAVM in the Fontan completed circulation, despite patent hepatic effluent flow, suggests involvement of a nonhepatic factor.

In the present study, no PAVM was identified when residual antegrade pulsatile flow was maintained (group III). This suggests a role for pulsatile flow but does not allow us to determine the relative roles of the hepatic factor (which is being supplied to the right lung even though in smaller quantity in group III) versus pulsatile flow.

Of note is the early appearance of PAVM, at only 3 months, in the time course after CPS. The development of PAVM is a time-dependent phenomenon usually requiring at least 1 to 2 years in humans before clinical and angiographic evidence appears. ${ }^{20}$ Our results are in contrast with a recent study in rats in which beyond 4 months, the microvessel density in the shunted lung was significantly higher, but angiographically evident PAVM occurred only beyond 10 months. ${ }^{21}$

Our results also corroborate the findings that sensitive diagnostic tools (contrast echography, hyperoxia test) ${ }^{6,10,22}$ demonstrate right to left shunting earlier than angiography. At 3 months, in group II, despite negative angiography, the more sensitive tests demonstrated occurrence of PAVM in the right lung.

\section{Pulmonary Hypertension}

Several reasons account for endothelial dysfunction after the Fontan procedure. The Fontan circulation alters pulmonary flow by loss of pulsatility and dependence of flow on negative intrathoracic pressure and diastolic ventricular function. Pulsatility is important for maintaining a low resistance in the pulmonary vasculature by shear stress-mediated release of endothelium-derived nitric oxide, causing endothelial relaxation, and passive recruitment of capillaries. ${ }^{23}$ Pulsatile pulmonary blood flow also results in passive capillary recruitment. When cardiac output increases in a normal individual, for example, during exercise, previously underperfused capillaries are recruited, thereby responding to the increase in flow by decreasing PVR. Overall, the underlying mechanism behind increased PVR in Fontan cases is unclear and likely to be multifactorial.

The present experiment demonstrated a significant increase of right PAP and PVR compared with the left lung in group II (no pulsatile flow), whereas in group III, the increase in right PAP and right PVR was mitigated (although still significantly higher than in the sham group). This demonstrates that the lack of pulsatility plays a central role in the emergence of pulmonary hypertension in Fontan circuits and that residual antegrade pulsatility results in a limitation in the increase in PAP. In regard to PAVM, our results showed that pulmonary hypertension in this model also occurs early in the time course after anastomosis.

\section{Capillary Recruitment}

Conflicting concepts exist between the fact that pulmonary capillaries are recruited by pulsatile flow ${ }^{24}$ and that microvessel density increases after CPS. In the current study, histologic features of shunted right lungs also demonstrated a higher number of capillaries. This phenomenon is likely to represent an early adaption mechanism of pulmonary vasculature to pulsatility loss. The decrease in shear stress caused by nonpulsatile flow might lead to endothelial dysfunction and an upregulation of angiogenesis in the pulmonary vasculature. As shown by blood gas analysis, the right lungs of group II demonstrated significantly higher gas exchange performance $\left(\mathrm{PO}_{2}\right.$ and $\mathrm{PCO}_{2}$ pulmonary arteriovenous difference) when compared with the left lungs. Group III demonstrated an even better performance, possibly because preserved micropulsatility increased gas exchange efficiency as the result of an enhanced capillary bed and the lack of PAVM. During the hyperoxic test, the PVR decreased and enhanced flow opened latent PAVM, resulting in a limited $\mathrm{Po}_{2}$ increase in group II.

The present experiment also can be used as a model of chronic hypoxia. Groups II and III had significantly lower $\mathrm{SaO}_{2}$ and $\mathrm{Po}_{2}$ when compared with group I. The role of chronic hypoxia in angiogenesis is clearly demonstrated, ${ }^{25}$ and its implication in capillary density augmentation has to be further explored with implementation of the presented model.

\section{Study Limitations}

Our model differs from the human condition in a number of ways. First, and as noted on the PVR evolution of the sham group through growth, porcine pulmonary vasculature demonstrates a prolonged decrease of PVR compared with human physiology. Second, these are juvenile pigs that have not possessed single-ventricle physiology. Third, the pulmonary vasculature of an infant with single-ventricle physiology and chronic cyanosis might respond differently after bidirectional CPS than the porcine pulmonary vasculature. For all these reasons, caution should be exercised in extrapolating these findings to clinical scenarios. However, these animals developed PAVM that appears to be echocardiographically and histologically the same as in humans regardless of the underlying physiology. 
Confounding factors may have impeded the analysis of pathogenesis of right pulmonary abnormalities in group II. Indeed, it is impossible to discriminate between the effect of pulsatility privation and the effect of hepatic venous effluent suppression. Creation of an inferior vena cava to PA shunt to achieve steady (nonpulsatile) flow including hepatic venous effluent may solve this dilemma, but may be prohibitively difficult in a large animal.

\section{CONCLUSIONS}

We have developed a chronic large animal model of bidirectional cavopulmonary anastomosis that can be used for variations of flow type and amount. Preservation of a small amount of residual antegrade pulsatile flow prevented the onset of PAVM and attenuated, but did not suppress, the emergence of early pulmonary hypertension. These lungs also showed better gas exchange capabilities. From a clinical standpoint, these data would support keeping a small amount of antegrade pulsatile flow during creation of a bidirectional CPS.

The authors thank Dr Pascal Chiari for critical appraisal of the article and constructive comments, and Nicole Walch, professional draftswoman, for helpful assistance.

\section{References}

1. d'Udekem Y, Iyengar AJ, Cochrane AD, Grigg LE, Ramsay JM, Wheaton GR, et al. The Fontan procedure: contemporary techniques have improved longterm outcomes. Circulation. 2007;116:I157-64.

2. Beghetti M. Fontan and the pulmonary circulation: a potential role for new pulmonary hypertension therapies. Heart. 2010;96:911-6.

3. Bridges ND, Jonas RA, Mayer JE, Flanagan MF, Keane JF, Castaneda AR. Bidirectional cavopulmonary anastomosis as interim palliation for high-risk Fontan candidates. Early results. Circulation. 1990;82:IV170-6.

4. Tanoue Y, Sese A, Ueno Y, Joh K, Hijii T. Bidirectional Glenn procedure improves the mechanical efficiency of a total cavopulmonary connection in high-risk Fontan candidates. Circulation. 2001;103:2176-80.

5. Jonas RA. Indications and timing for the bidirectional Glenn shunt versus the fenestrated Fontan circulation. J Thorac Cardiovasc Surg. 1994;108:522-4.

6. Bernstein HS, Brook MM, Silverman NH, Bristow J. Development of pulmonary arteriovenous fistulae in children after cavopulmonary shunt. Circulation. 1995; 92:309-14.

7. Triedman JK, Bridges ND, Mayer JE, Lock JE. Prevalence and risk factors for aortopulmonary collateral vessels after Fontan and bidirectional Glenn procedures. J Am Coll Cardiol. 1993;22:207-15.
8. Gérelli S, Boulitrop C, Van Steenberghe M, Maldonado D, Bojan M, Raisky O, et al. Bidirectional cavopulmonary shunt with additional pulmonary blood flow: a failed or successful strategy? Eur J Cardiothorac Surg. 2012;42:513-9.

9. Santamaria F, Sarnelli P, Celentano L, Farina V, Vegnente A, Mansi A, et al. Noninvasive investigation of hepatopulmonary syndrome in children and adolescents with chronic cholestasis. Pediatr Pulmonol. 2002;33:374-9.

10. Larsson ES, Solymar L, Eriksson BO, de Wahl Granelli A, Mellander M. Bubble contrast echocardiography in detecting pulmonary arteriovenous malformations after modified Fontan operations. Cardiol Young. 2001;11:505-11.

11. Webber SA, Horvath P, LeBlanc JG, Slavik Z, Lamb RK, Monro JL, et al. Influence of competitive pulmonary blood flow on the bidirectional superior cavopulmonary shunt. A multi-institutional study. Circulation. 1995;92:II279-86.

12. Mainwaring RD, Lamberti JJ, Uzark K, Spicer RL. Bidirectional Glenn: is accessory pulmonary blood flow good or bad? Circulation. 1995;92:II294-7.

13. Berdat PA, Belli E, Lacour-Gayet F, Planche C, Serraf A. Additional pulmonary blood flow has no adverse effect on outcome after bidirectional cavopulmonary anastomosis. Ann Thorac Surg. 2005;79:29-36.

14. Turner ME, Richmond ME, Quaegebeur JM, Shah A, Chen JM, Bacha EA, et al. Intact right ventricle-pulmonary artery shunt after stage II palliation in hypoplastic left heart syndrome improves pulmonary artery growth. Pediatr Cardiol. November 15, 2012 [Epub ahead of print].

15. Moore JW, Kirby WC, Madden WA, Gaither NS. Development of pulmonary arteriovenous malformations after modified Fontan operations. J Thorac Cardiovasc Surg. 1989;98:1045-50.

16. Kopf GS, Laks H, Stansel HC, Hellenbrand WE, Kleinman CS, Talner NS Thirty-year follow-up of superior vena cava-pulmonary (Glenn) shunts. J Thorac Cardiovasc Surg. 1990;100:662-71.

17. Reddy VM, McElhinney DB, Moore P, Bristow J, Haas GS, Hanley FL. An in stitutional experience with the bidirectional cavopulmonary shunt: do we know enough about it? Cardiol Young. 1997;7:274-83.

18. Marianeschi SM, McElhinney DB, Reddy VM. Pulmonary arteriovenous malformations in and out of the setting of congenital heart disease. Ann Thorac Surg. 1998;66:688-91

19. Kwon BS, Bae EJ, Kim GB, Noh CI, Choi JY, Yun YS. Development of bilateral diffuse pulmonary arteriovenous fistula after Fontan procedure: is there nonhepatic factor? Ann Thorac Surg. 2009;88:677-80.

20. Bernstein HS, Ursell PC, Hanley FL, Brook MM, Silverman NH, Bristow J. Fulminant development of pulmonary arteriovenous fistulae in an infant following total cavopulmonary shunt. Pediatr Cardiol. 1996;17:46-50.

21. Starnes SL, Duncan BW, Fraga CH, Desai SY, Jones TK, Mathur SK, et al. Rat model of pulmonary arteriovenous malformations after right superior cavopulmonary anastomosis. Am J Physiol. 2002;283:H2151-5.

22. Feinstein JA, Moore P, Rosenthal DN, Puchalski M, Brook MM. Comparison of contrast echocardiography versus cardiac catheterization for detection of pulmonary arteriovenous malformations. Am J Cardiol. 2002;89:281-5.

23. Raj JU, Kaapa P, Anderson J. Effect of pulsatile flow on microvascular resistance in adult rabbit lung. J Appl Physiol. 1992;72:73-81.

24. Presson RG Jr, Baumgartner WA Jr, Peterson AJ, Glenny RW, Wagner WW Jr. Pulmonary capillaries are recruited during pulsatile flow. J Appl Physiol. 2002; 92:1183-90

25. Howell K, Preston RJ, McLoughlin P. Chronic hypoxia causes angiogenesis in addition to remodelling in the adult rat pulmonary circulation. J Physiol. 2003; 547:133-45 